\title{
EL LABORATORIO DEL URÓLOGO
}

Francisco Javier Ruíz Marcellán

Servicio de Urología. Instituto Dexeus. Barcelona. España.

Resumen.- Aportación de la relación personal del autor con D. Luis Cifuentes. Se enfatiza sobre la importancia de visualizar el sendimento urinario en la consulta del urólogo.

Palabras clave: Laboratorio del urólogo. Sedimento. Cristaluria. Luis Cifuentes Delatte.

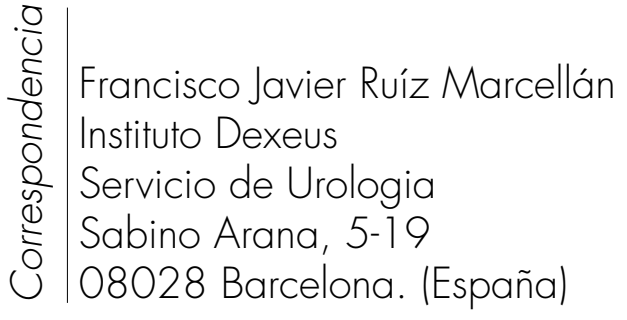

Summary.- Description of the author' personal relationship with Dr. Luis Cifuentes. We emphasize the importance of microscopic evaluation of urine sediment in the office of the urologist.

Keywords: That laboratory of the urologist. Urine sediment. Crystalluria. Dr. Luis Cifuentes Delatte.

\section{INTRODUCCIÓN}

La urología como especialidad se afianza y consolida en las primeras décadas del siglo XX. La introducción de la urografía I.V., la endoscopia diagnóstica y quirúrgica, el perfeccionamiento de la cirugía conservadora del aparato urinario, el transplante de riñón y la solidez de los grandes servicios urológicos europeos y americanos modulan una especialidad enormemente atractiva.

En el trabajo, el urólogo ha de dedicar mucho tiempo en las exploraciones, diagnóstico y tratamiento médico. El residente de urología precisa una formación acrisolada en endocrinología y metabolismo mineral, andrología, oncología, bacteriología, biología molecular, etc.

Un buen urólogo debe formular con toda precisión las indicaciones operatorias y dominar la cirugía abierta, endoscópica y laparoscópica. El éxito de su cirugía se basará siempre en una técnica depurada unida a un correcto diagnóstico, y todo ello lo más rápidamente posible y con las menores molestias para el paciente.

En los primeros años de la década de los setenta, inicié mi andadura urológica en la cátedra 


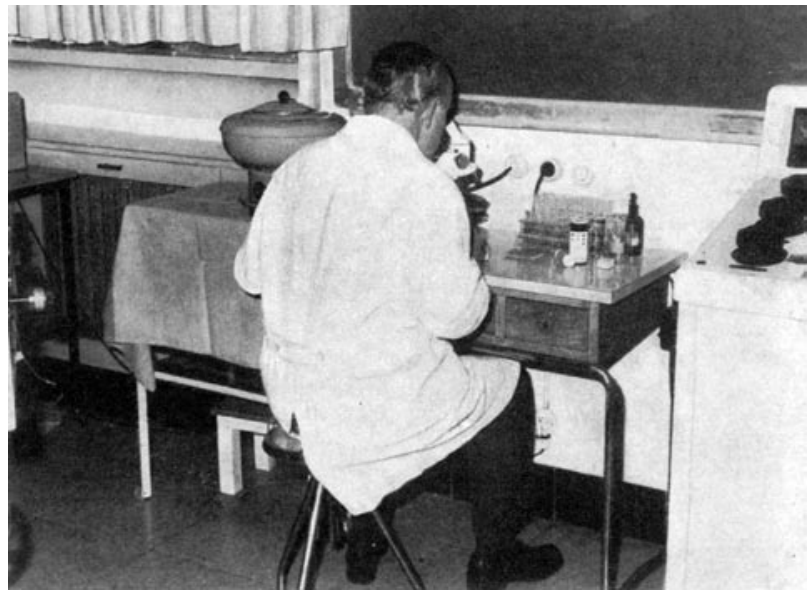

FIGURA 1

del Prof. F. Romero Aguirre de Zaragoza. Proseguí mi etapa de médico residente en el servicio de urología del actual Hospital Valle Hebrón al lado de mi maestro F. Solé Balcells.

En aquella época las publicaciones interesantes en lengua castellana eran escasas y las fuentes de nuestra formación se centraban en la Enciclopedia Francesa de Urología y el Campbell's Urology.

En estos años descubrí las valiosas y meritorias publicaciones del Prof. Luís Cifuentes. Su libro de Cistitis y Cistopatías publicado en 1947, su espectacular libro de Cirugía Urológica Endoscópica publicado en 1961 y El Laboratorio del Urólogo publicado en 1974.

Recuerdo estas tres publicaciones como una fuente inagotable de información que afianzaron y marcaron un sello específico en mi estilo de estudiar, diagnosticar y tratar la enfermedad urológica.

El Laboratorio del Urólogo condicionó mimetizar criterios y actitudes en mi consulta, disponiendo siempre de un pequeño laboratorio. (Figuras 1 y 2 ).

El Profesor Cifuentes consideraba que era de gran utilidad la observación directa del sedimento urinario obtenido por centrifugación y bajo visión directa de un microscopio de contraste de fases.

En el prólogo de su libro dice textualmente: "Desearíamos convencer a los urólogos jóvenes que interpretar correctamente los datos que proporciona la observación microscópica de un sedimento es un acto tan directamente urológico como realizar una correcta hemostasia en una prostatectomía."

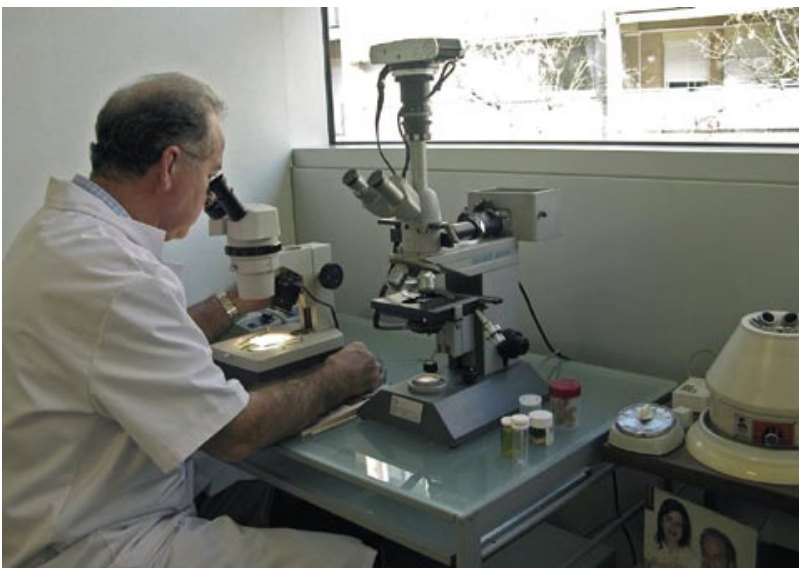

FIGURA 2.

El pequeño laboratorio del urólogo precisa de una centrífuga, microscopio de contraste de fases, lupa binocular, algunos tubos y unos pocos reactivos.

En el estudio microscópico del sedimento urinario podemos encontrar: hematíes, leucocitos, bacterias, hongos, células neoplásicas y cristales.

Una de las ventajas del microscopio de fases es la nitidez con que aparecen en tono gris oscuro gérmenes de muy diferentes clases, que son difíciles de ver en el microscopio óptico normal.

La observación del sedimento a escasos minutos de haber recogido la orina en la consulta es grande, porque se evitan los errores de contaminación y de crecimiento de gérmenes extraños.

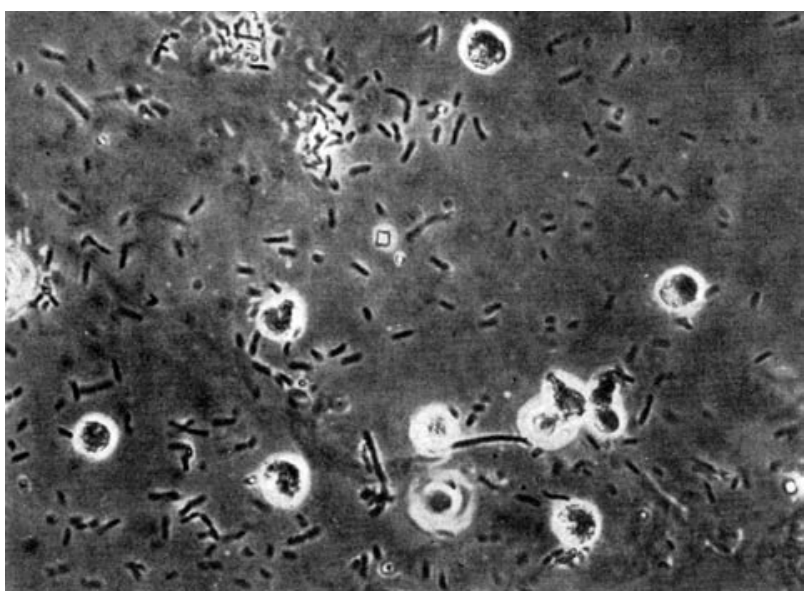

FIGURA 3 


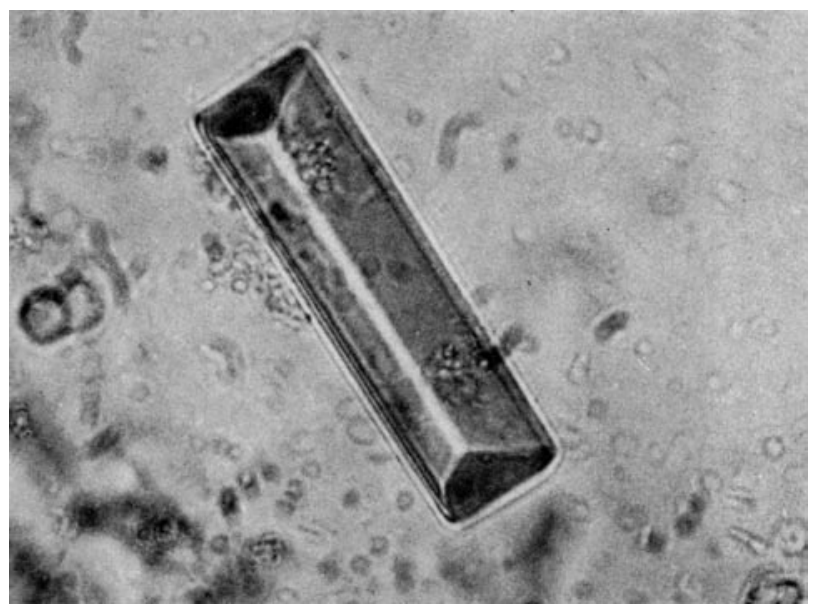

FIGURA 4

Los gérmenes bacilares, en forma de bastón, destacan con toda precisión, pudiendo apreciarse si tienen o no movilidad (Figura 3).

En otros enfermos se puede encontrar que la orina tiene una reacción fuertemente alcalina y que aparecen en su sedimento cristales de fosfato amónico magnésico, pensando con casi absoluta seguridad que se trata de un germen ureolítico (proteus) (Figura 4).

Cuando se tiene experiencia en visualizar muchos sedimentos en orinas recien emitidas y centrifugadas se aprecian cristales auténticos.

Es fácil ver cristales bipiramidales de oxalato cálcico, los llamados cristales en "sobre de carta" (Figura 5).

Es frecuente ver también cristales amorfos de fosfato cálcico.

Los cristales de ácido úrico se presentan de formas muy distintas. Son concreciones microscópicas de color amarillo, dorado o ambarino. Se presentan con perfil en forma de huso, con láminas planas y formas hexagonales o romboidales.

Los cristales de cistina son muy peculiares y raros. Son láminas hexagonales formando a veces figuras geométricas. La cistinuria no es frecuente y dentro de estos enfermos tampoco es frecuente la aparición de los típicos cristales. Por tanto, hay que efectuar la reacción química que informa sobre la presencia de cistina en la orina.

La orina es la mensajera de muchas patologías del aparato urinario. Como urólogo tengo la

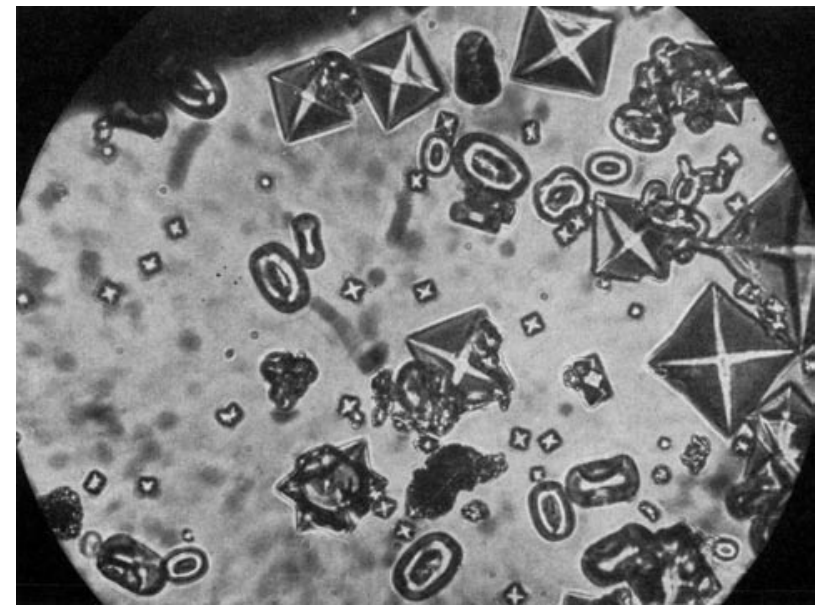

FIGURA 5.

personal experiencia de lo mucho que ayuda para hacer un juicio clínico el conocimiento de las anormalidades del sedimento.

El estudio inmediato del sedimento evita alteraciones y errores como la alcalinización amoniacal.

En los enfermos litiásicos es especialmente de gran utilidad puesto que orienta y diagnostica la mayor parte de los diferentes cálculos: oxalato cálcico, ácido úrico, estruvita o cistina.

Como urólogo especializado en el manejo del enfermo litiásico disfruté en el año 1984 con la aparición de su gran obra: Composición y Estructura de los Cálculos Renales. Este libro es la cristalización de la gran obra intelectual de Don Luís y un paradigma de la investigación médica en urología.

Don Luís Cifuentes con Aurelio Rapado inocularon el "virus" de la litiasis a un grupo numeroso de urólogos que acudíamos a la Fundación Jiménez Díaz a sus Reuniones y Congresos durante dos décadas. En esta época pude compartir conversaciones, correspondencia e inquietudes con el Prof. Luís Cifuentes.

Su especial personalidad científica manifestada en sus libros y enseñanza marcó un sello especial en mi formación y en mi estilo de trabajo cotidiano.

Tengo el convencimiento de que la mayor parte de los urólogos de habla hispana tenemos un sentimiento de agradecimiento profundo a la labor científica que nos ha legado Don Luís. 